\title{
Cultural and Morphological Variations of Fusarium solani (Mart.) Sacc. Causing Root Rot of Patchouli in Assam, India
}

\author{
Monuj Gogoi", D.K. Sarmah and S. Ali \\ Department of Plant Pathology, Assam Agricultural University, Jorhat-785013, Assam, India \\ *Corresponding author
}

A B S T R A C T

\begin{abstract}
Keywords
Cultural and morphological

variations, Root rot.

Article Info

Accepted:

15 September 2017

Available Online:

10 November 2017 from $81.55 \mathrm{~mm}$ to $90.00 \mathrm{~mm}$ at ten days after inoculation on PDA medium. The fastest radial growth $(90.00 \mathrm{~mm})$ was observed in isolates $\mathrm{JFS}_{1}, \mathrm{JFS}_{2}$ and $\mathrm{NFS}_{4}$ followed by isolates $\mathrm{GFS}_{8}(87.56 \mathrm{~mm}), \mathrm{BFS}_{6}(87.46 \mathrm{~mm}), \mathrm{NFS}_{3}(85.34 \mathrm{~mm})$ and $\mathrm{NFS}_{5}(84.78 \mathrm{~mm})$ whereas minimum radial growth was observed in isolate $\mathrm{BFS}_{7}(81.88 \mathrm{~mm})$. All isolates produced micro, macro-conidia and chlamydospores. The size of macro conidia was ranged from 13-15 x 3-4 $\mu \mathrm{m}$ to $27-29 \times 4-5 \mu \mathrm{m}$, size of micro conidia was ranged from 3-4 x 1-2 $\mu \mathrm{m}$ to $9-10 \times 1-3 \mu \mathrm{m}$, the number of septa in macro and micro conidia are 2-4 and 01 respectively and the colour is hyaline. All conidia were hyaline and macro conidia were sickle shaped with the blunt end, micro conidia was cylindrical and round to oval and chalamydospore were intercalary, terminal, globose to oval shaped in all the isolates. The septation of macro conidia is 2-4 and micro conidia were $0-1$. Conidiophores were elongated and sparsely branched, each branch usually terminated with a spore bearing phialide. The most distinguished characters of long monophialidic conidiogenous cells were observed in all the isolates.
\end{abstract}

Root rot disease of patchouli is caused by Fusarium solani (Mart.) Sacc. Eight isolates were collected from patchouli growing areas of Assam to study the cultural and morphological characteristics of $F$. solani. The colony diameter of eight isolates ranged

\section{Introduction}

Patchouli (Pogostemon cablin (Blanco) Benth.) plant is an important perennial aromatic plant belongs to lamiaceae family. Patchouli is commercially cultivated in India, Bangladesh, Nepal, Sri Lanka, Myanmar, Thailand and China. It also grows wild in Singapore, Indonesia and Malaysia but owing to high demand of its essential oil, used in cosmetics, breath fresheners, flavoring baked foods, sausages, etc. (Singh and Rao, 2009; Puttana et al., 2005). In India, Commercial cultivation of patchouli plant was first initiated and practiced by Tata Oil Mills in the year 1942. However, after its initial stray attempts of cultivation, an organized cultivation practice was established by CIMAP (Central Institute of Medicinal and Aromatic Plants), Bangalore, India in the year, 1962 (Kumar et al., 1986). Patchouli is cultivated in Assam, Madhya Pradesh, Tamil Nadu, Kerala and Karnataka. Currently, India is producing a small quantity of patchouli oil against its requirements of 40 tonnes of pure oil and about 70 tonnes of formulated oil. Hence, majority of these oils are being imported from Indonesia (Jadhav et al., 
2003). In northeast, Patchouli cultivation is started in the first instance on about 1000 ha land by farmers and entrepreneurs and planned to go up to five times in future (Das, 2001). Root rot of patchouli caused by $F$. solani is severe, destructive, wide spread and found in all patchouli growing areas of India. The typical symptoms of the disease are yellowing of lower leaves, drooping, and wilting of plant. Sreedevi et al., (2009) reported that the presence of cultural and morphological variability among the Fusarium solani isolated from different areas of Karnataka state, India. In the present studies isolates of $F$. solani (Mart.) Sacc. collected from four districts of Assam were studied for the presence of cultural and morphological variations among these isolates.

\section{Materials and Methods}

\section{Collection, isolation and identification of $\boldsymbol{F}$. solani isolates}

Eight isolates of $F$. solani were collected from different areas of Assam namely Herbal garden (AAU), Pokamura, Kaliabor Nursery, Seuj Nagar, Uluoni Gaon, Bijoypur, Madhupur, Sugarcane Research Station (SRS) (Buralikson) and were designated as $\mathrm{JFS}_{1}$, $\mathrm{JFS}_{2}, \mathrm{NFS}_{3}, \mathrm{NFS}_{4}, \mathrm{NFS}_{5} \mathrm{BFS}_{6}, \mathrm{BFS}_{6}$ and $\mathrm{GFS}_{8}$ For isolation of the pathogen, infected tissues of the root were cut into small pieces of 1-2 $\mathrm{cm}$ size and surface-sterilized with $0.1 \%$ sodium hypochlorite solution for one to two minute and washed repeatedly in sterilized water and placed in petri-plates containing PDA medium and incubated at $27 \pm 1^{\circ} \mathrm{C}$. The purified culture of the pathogen was obtained by hyphal tip method and sub-cultures from peripheral growth were made on PDA slants. The pure $F$. solani cultures were stored at $4{ }^{\circ} \mathrm{C}$ in refrigerator and used for further studies. Isolation of $F$. solani from different plants by following the standard tissue isolation techniques has been reported by several workers (Satyaprasad and Rama Rao, 1981; Kore and Patil, 1985; Kore and Mashalkar, 1987).

The pathogen isolates were mainly identified on the basis of cultural and morphological characters as Fusarium solani (Mart) Sacc. as described by Booth (1971). Further, the identity of $F$. solani was confirmed from National Center of Fungal Taxonomy, New Delhi (I.D. No.-9080.17). The fungus also produced wilt and typical root rot symptoms under pathogenicity test. Thus, Fusarium sp. understudy was identified and confirmed as $F$. solani.

\section{Symptomatology}

Following symptoms of patchouli root rot caused by $F$. solani were observed during the study.

\section{Root rot of patchouli}

Patchouli plants showed wilting at all stages of their growth. Yellowing of the older leaves was the first external symptom which later advanced to middle and terminal leaves. Drooping of green parts followed exactly as if there was not enough moisture in the soil. Brown to black discolouration of stem and roots was observed followed by dark brown discolouration of vascular tissue. Severe disintegration of primary and secondary roots surface was also observed. Ultimately, the whole plant dried and there was premature death of the plant.

\section{Cultural variability}

Eight isolates of $F$. solani (Mart.) Sacc. were collected from different places were grown on PDA for variability studies. The petri-plates (90 $\mathrm{mm}$ ) containing $15-20 \mathrm{ml}$ of PDA medium were inoculated aseptically with 5 $\mathrm{mm}$ mycelial disc of the fungus from the periphery of actively growing culture and 
incubated at $27 \pm 1^{\circ} \mathrm{C}$ for 10 days. The observations were recorded on colony diameter, colony color, colony margin, pigmentation and surface elevation. The colony diameter of the isolates $(\mathrm{mm})$ was measured at 48, 72, 96, 144, 168, 216 and 240 hours after inoculation. All the isolates showed wide variations in respect of colony colour and pigmentation. The experiment was laid out in completely randomized design (CRD) with five replications. Colony diameter $(\mathrm{mm})$ was measured from three sides of the colony growth.

\section{Morphological variability}

Spores of $F$. solani of different isolates were measured from the pure culture of the pathogens. Spores were mixed with lacto phenol cotton blue thoroughly so that, a uniform spread is obtained and then cover slips was placed over it. Spores were measured under high power objectives (40x) using ocular and stage micrometer. The average size of the spores were then determined and shape of the spores were recorded. For micro and macroconidia, length and breadth of fifty (50) spores for each of three replications of all the isolates were measured using ten day old culture.

\section{Results and Discussion}

Cultural characteristics based on colony diameter $(\mathrm{mm})$ among the $F$. solani isolates

The colony diameter of eight isolates of $F$. solani was observed up to ten days and incubated at $27 \pm 1^{\circ} \mathrm{C}$. The highest colony diameter $(90 \mathrm{~mm})$ was observed in isolates $\mathrm{JFS}_{1}, \mathrm{JFS}_{2}$ and $\mathrm{NFS}_{4}$ followed by isolates $\mathrm{GFS}_{8}, \quad \mathrm{BFS}_{6}, \quad \mathrm{NFS}_{5}$ and $\mathrm{NFS}_{3}$ whereas minimum colony diameter was observed in isolate $\mathrm{BFS}_{7}$. Similar type of observations were also made by earlier worker Sreedevi et al., (2009) who studied cultural and morphological variability among eight isolates of $F$. solani causing fungal wilt of patchouli. Chandran and Kumar (2012) studied that radial growth of thirteen isolates of $F$. solani incitant of dry root-rot of citrus in Karnataka (Table 1).

\section{Colony characteristics on PDA}

The results presented in the Table 2 revealed that significant differences between isolates with respect to colony character, colony margin and pigmentation in culture plates. The colony coloured of the isolates were white in colour, colony margin of the isolates were vary from smooth to irregular. White colour cottony growth and raised mycelium with smooth margins was observed in JFS isolates. $\mathrm{JFS}_{2}$ isolates showed white cottony with fluffy growth mycelium. $\mathrm{NFS}_{3}$ isolates observed white dense growth with smooth margin. White sparse growth was observed in $\mathrm{NFS}_{4}$ isolates. $\mathrm{NFS}_{5}$ isolates showed white colour fluffy growth and irregular margin. White fluffy mycelium with irregular margins was observed in $\mathrm{BFS}_{6}$ isolates. Isolates $\mathrm{BFS}_{7}$ showed white fluffy mycelium with concentric ring and irregular margin. White raised cottony mycelium and irregular mycelium was observed in $\mathrm{GFS}_{8}$. Chandran and Kumar (2012) while studying variability of $F$. solani isolates found six isolates as white sparse growth, three as white cottony growth, two as white fluffy and three as white dense growths. Similar types of results were also made by earlier workers (Champawat and Pathak, 1989; Madhukeshwara, 2000; Vettraino et al., 2009 and Sreedevi et al., 2009).

Based on colony pigmentation isolates were assigned to three groups as par "Royal Horticultural Society Colour Chart, London". They were classified as Yellow, Purple and Orange. Two isolates were found purple (JFS and $\mathrm{JFS}_{2}$ ), four isolates were found yellow $\left(\mathrm{NFS}_{3}, \mathrm{NFS}_{4}, \mathrm{NFS}_{5}, \mathrm{NFS}_{6}, \mathrm{NFS}_{7}\right)$ and one isolate $\left(\mathrm{GFS}_{8}\right)$ was orange. 


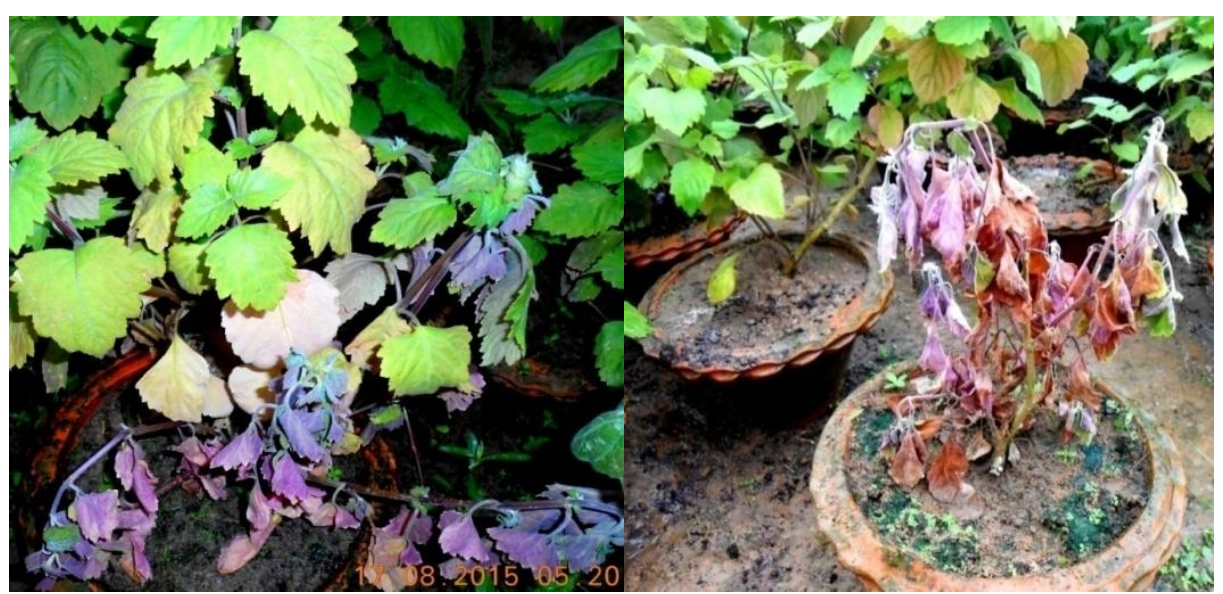

A. Initial wilting and dropping of lower parts

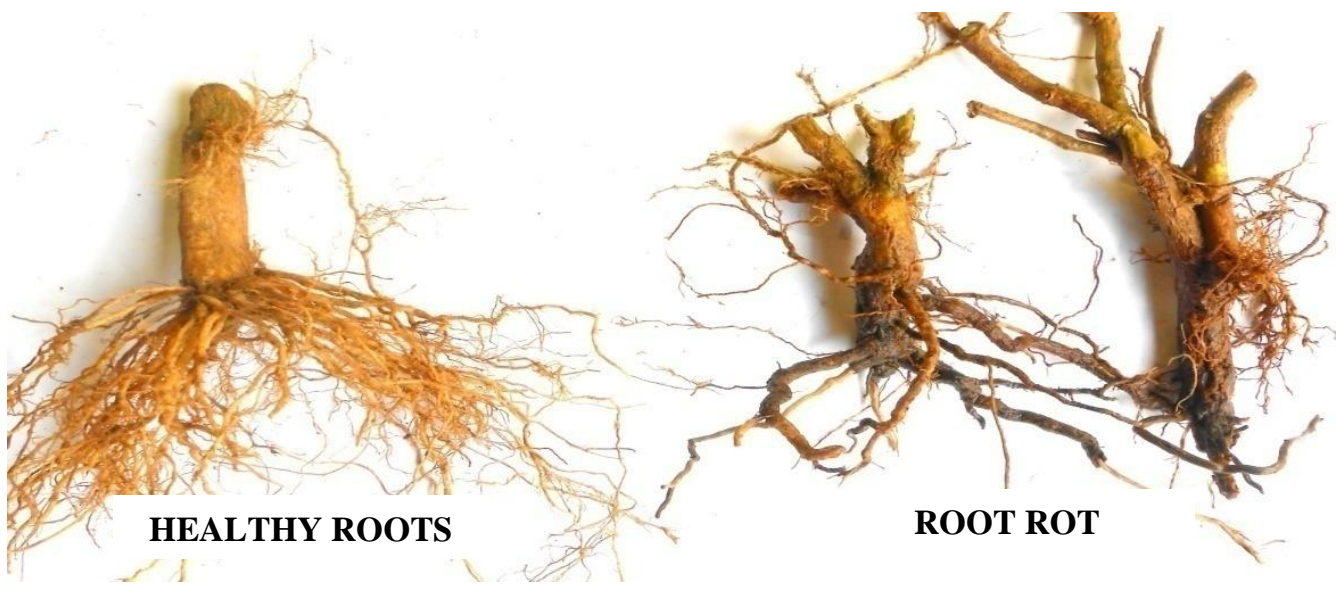

B. Healthy roots and infected root rot of patchouli plant

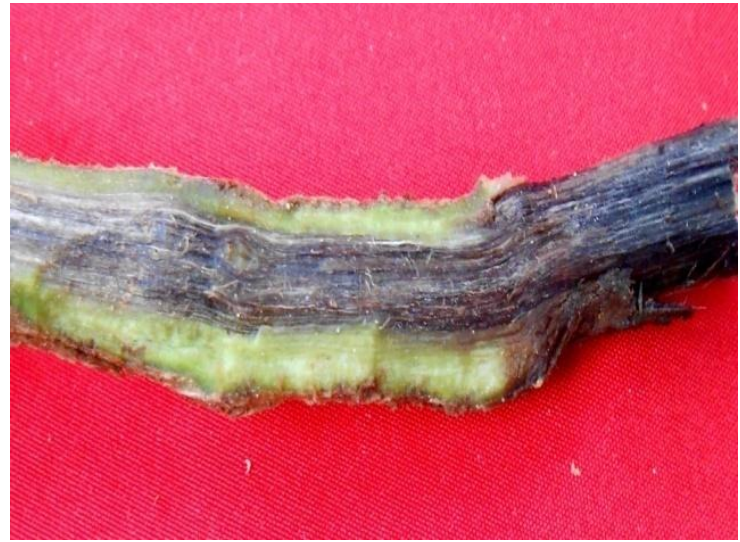

C. Black vascular discoloration of infected stem

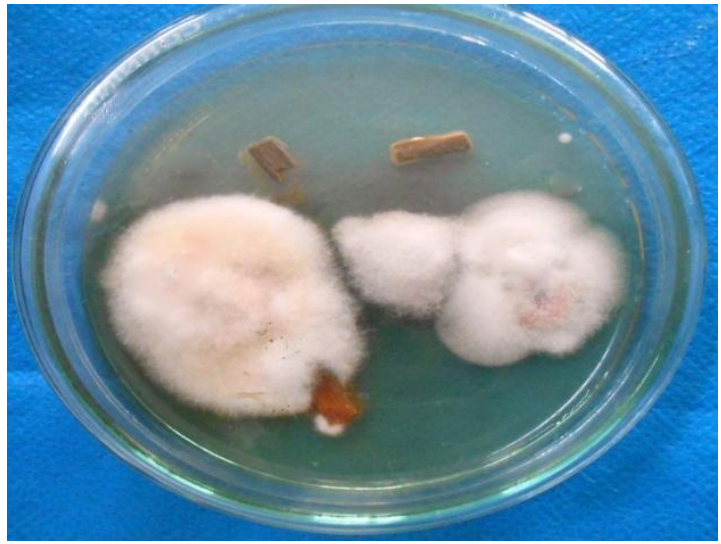

D. Isolation of F.solani from

Plate.1 (A-D) Typical symptoms of wilting, root rot and vascular discoloration of patchouli plants 


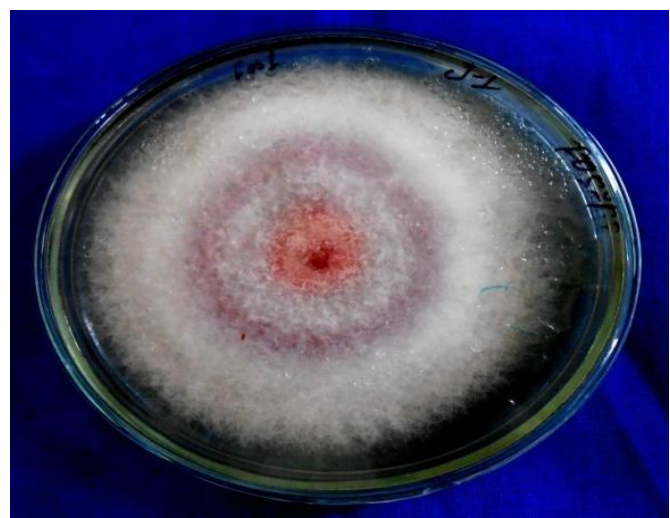

$\mathrm{JFS}_{1}$
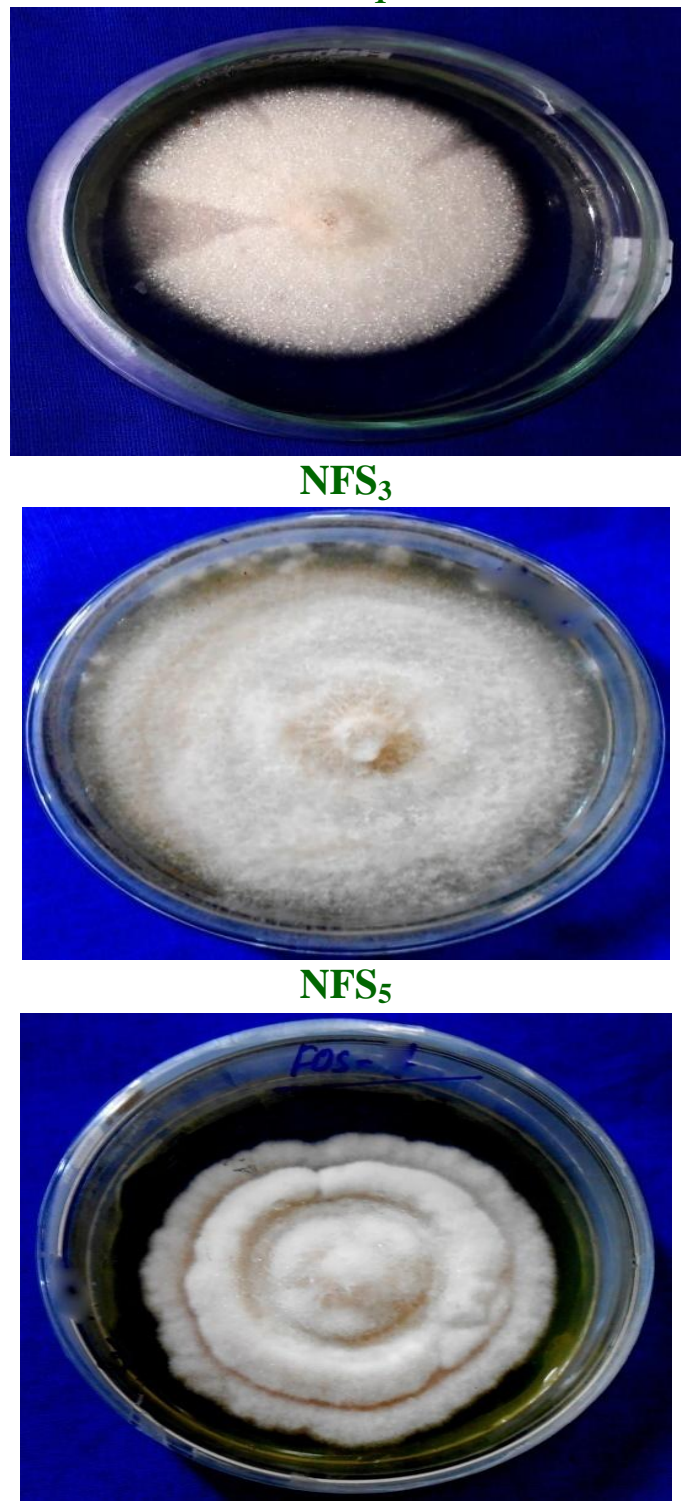

$\mathrm{BFS}_{7}$

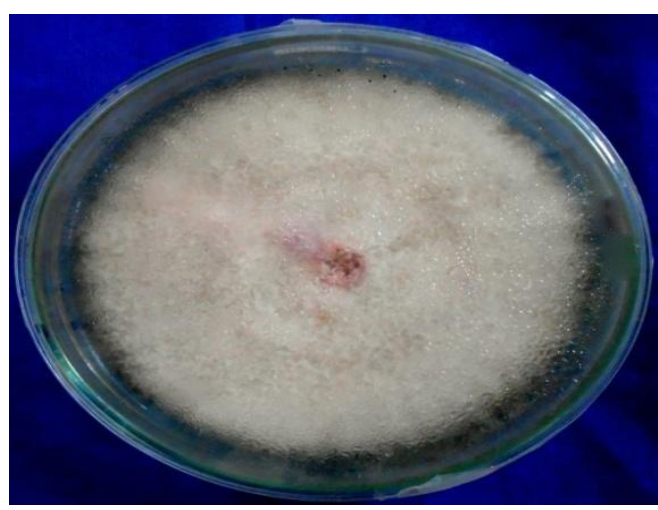

$\mathrm{JFS}_{2}$

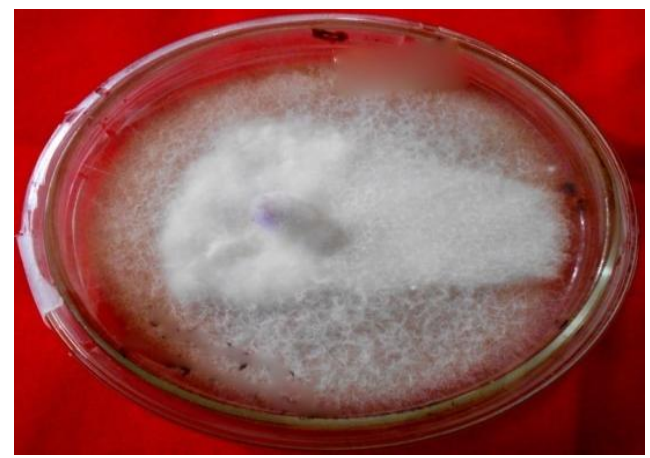

$\mathrm{NFS}_{4}$

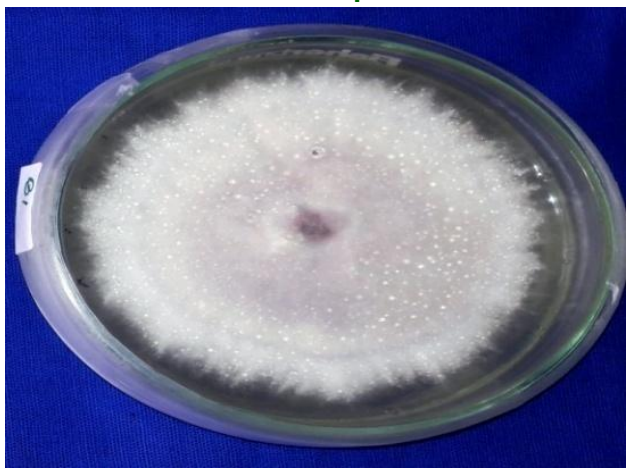

$\mathrm{BFS}_{6}$

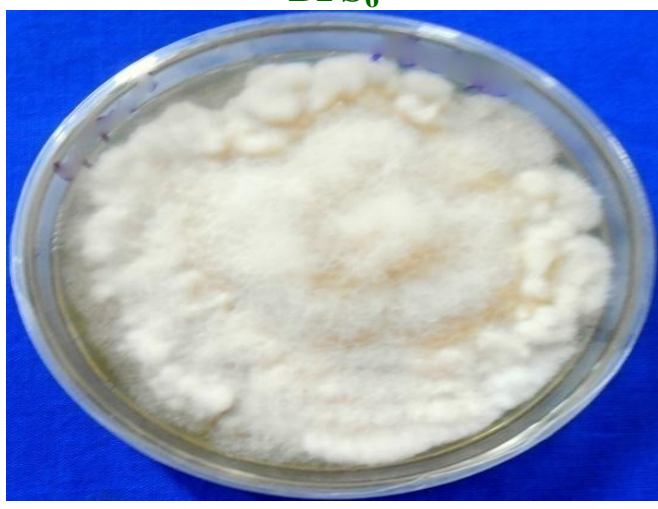

GFS $_{8}$

Plate.2 Pure culture of different isolates of $F$. solani on PDA 


\section{FRONT VIEW REVERSE VIEW}

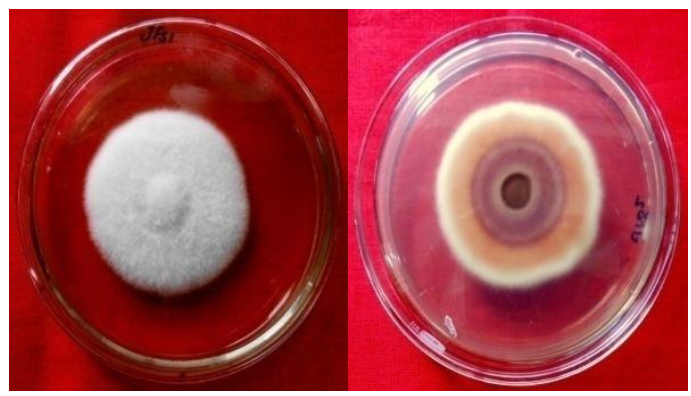

A. JFS $_{1}$

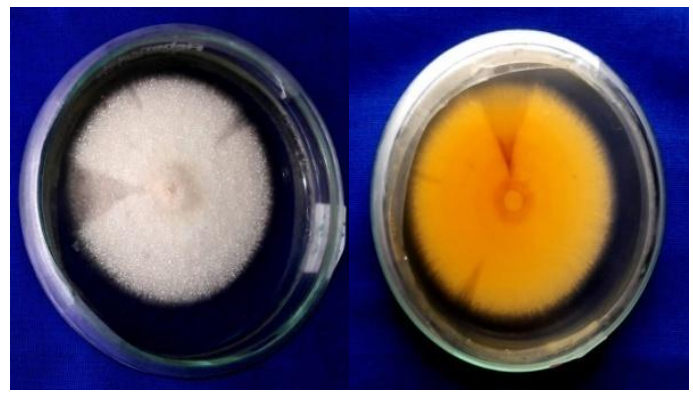

C. $\mathrm{NFS}_{3}$

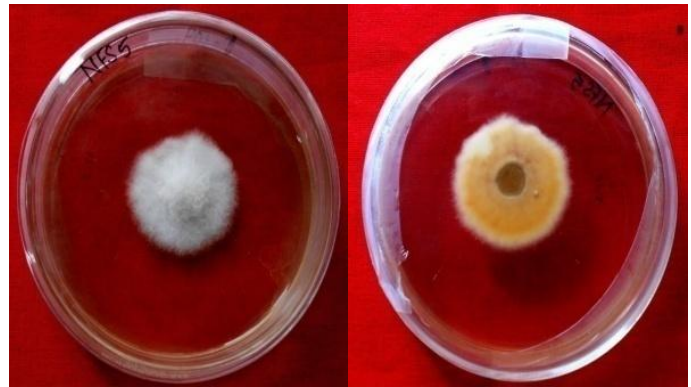

E. $\mathrm{NFS}_{5}$

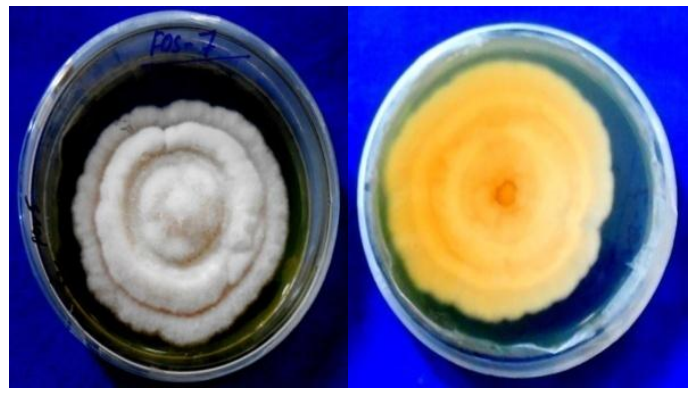

G. $\mathrm{BFS}_{7}$
FRONT VIEW REVERSE VIEW

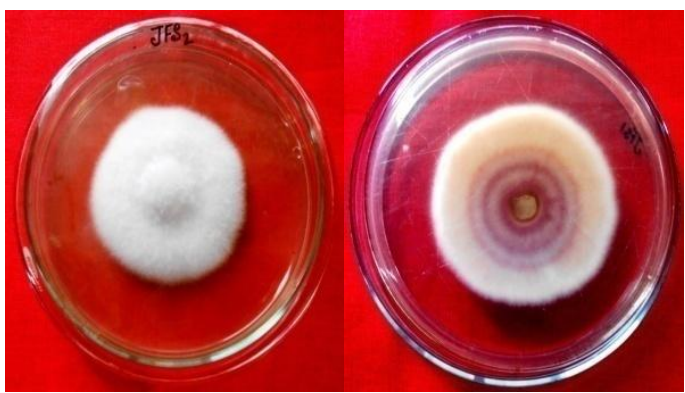

B. $\mathbf{J F S}_{2}$

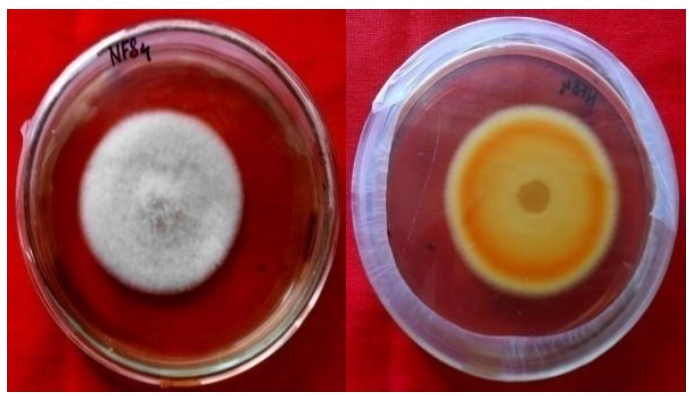

D. $\mathrm{NFS}_{4}$

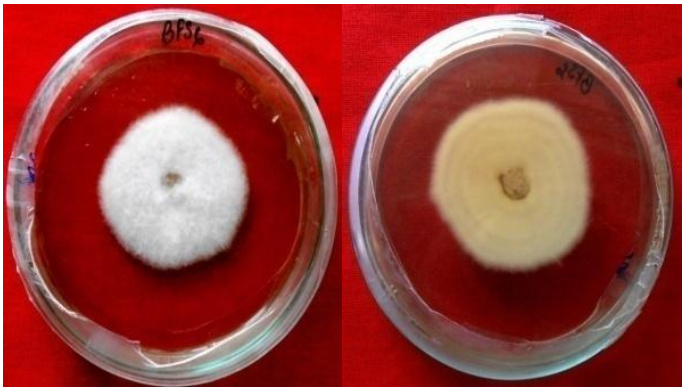

F. BFS $_{6}$

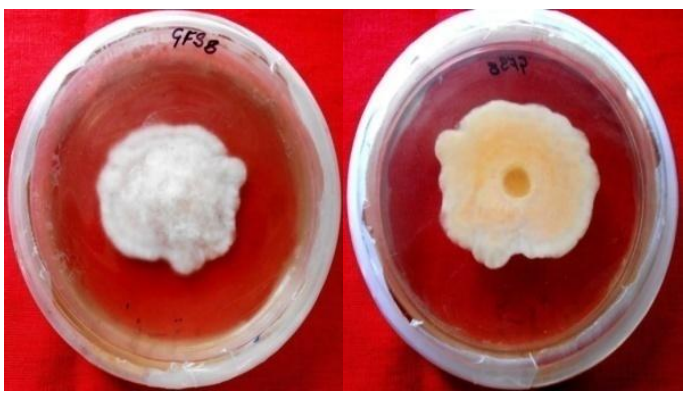

H. GFS $_{8}$

Plate.3 (A-H) Cultural variability of different isolates of Fusarium solani 


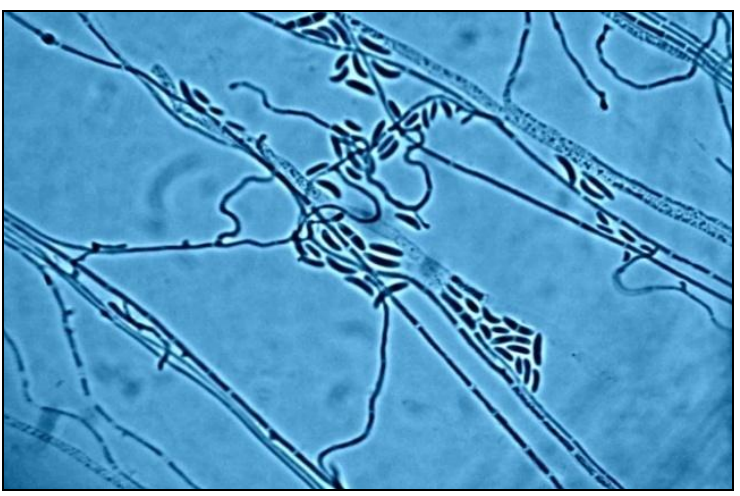

A. JFS 1

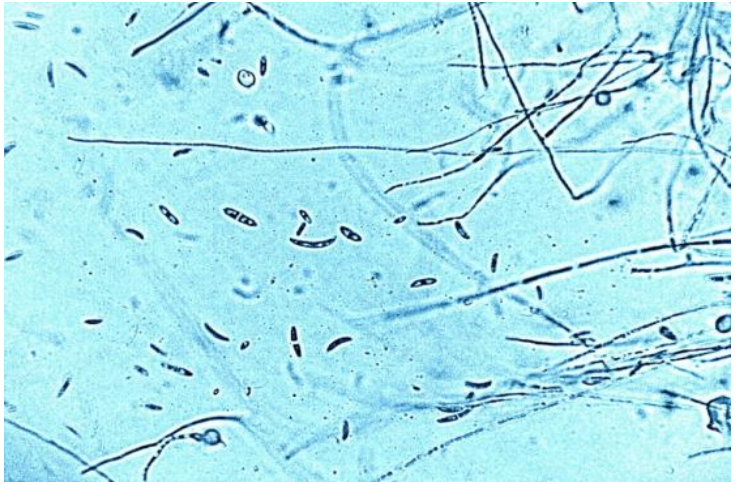

C. $\mathrm{NFS}_{3}$

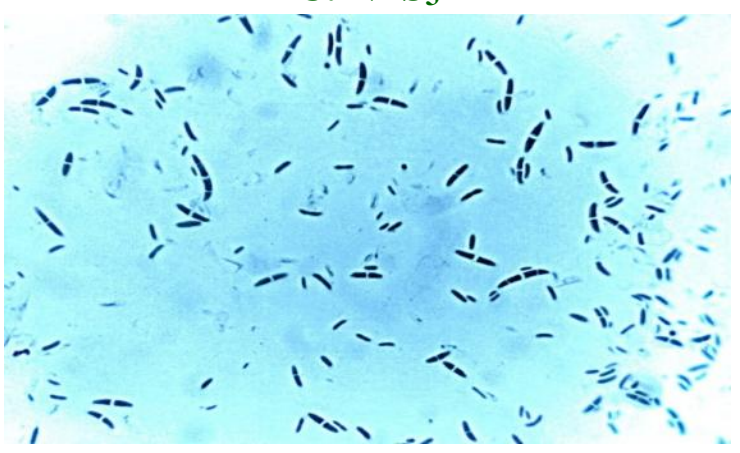

E. $\mathrm{NFS}_{5}$

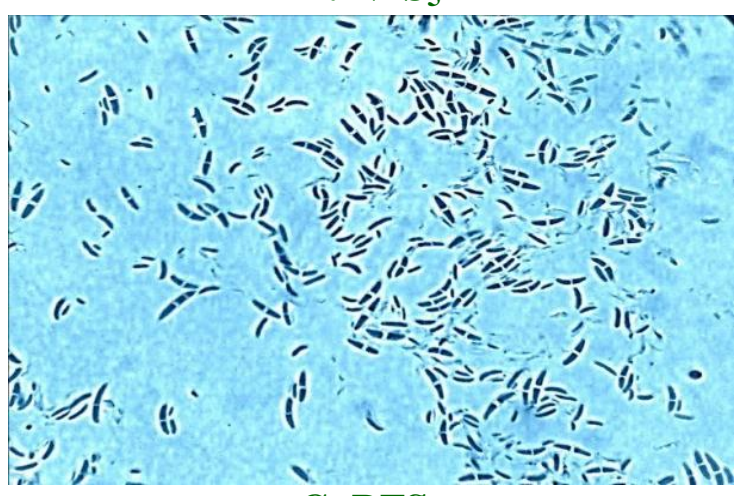
G. $\mathrm{BFS}_{7}$

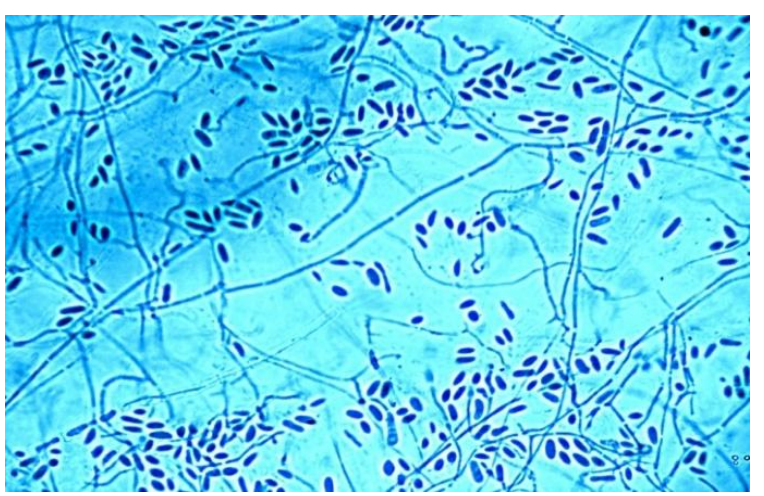

B. JFS 2

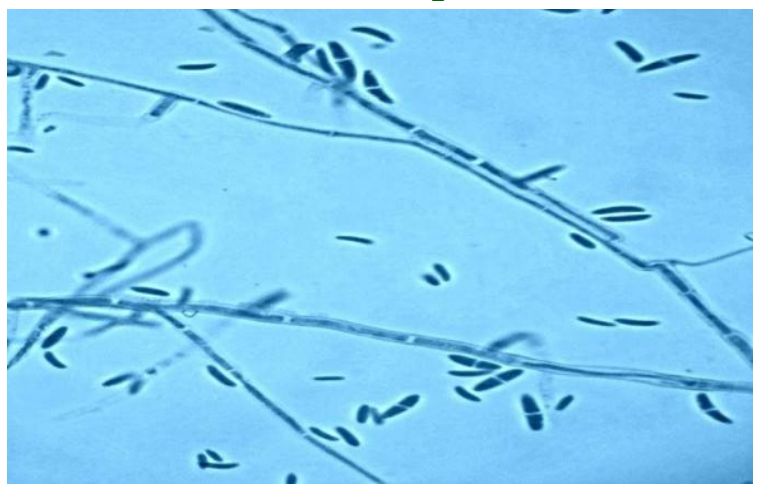

D. $\mathrm{NFS}_{4}$

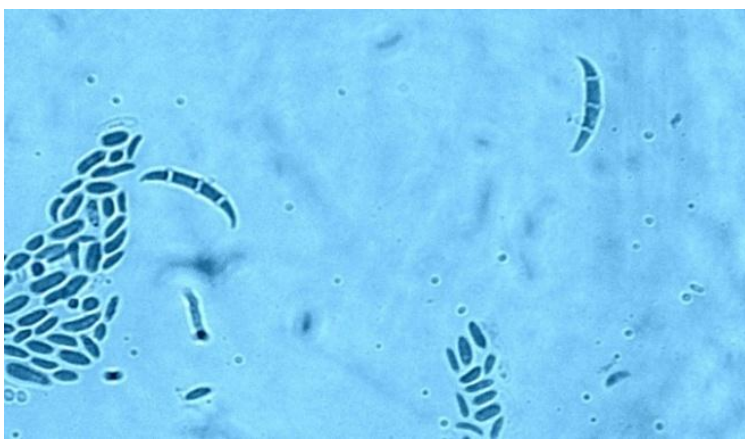

F. $\mathrm{BFS}_{6}$

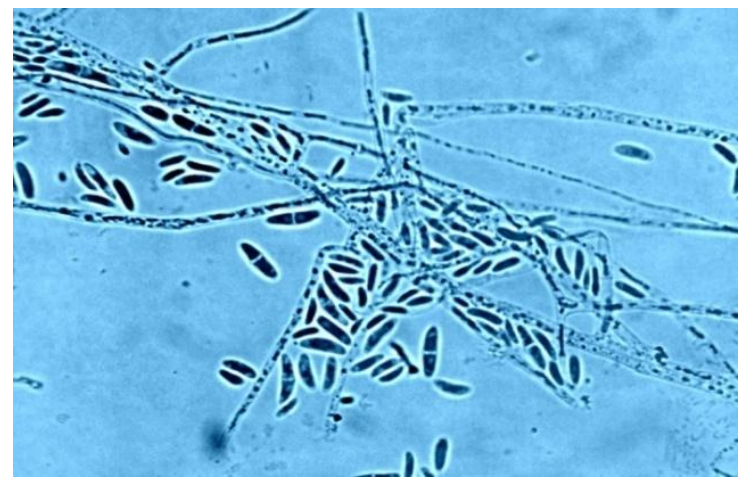

H. GFS 8

Plate.4 (A-H) Photomicrograph of micro-conidia of different isolates of F. solani (40X) 


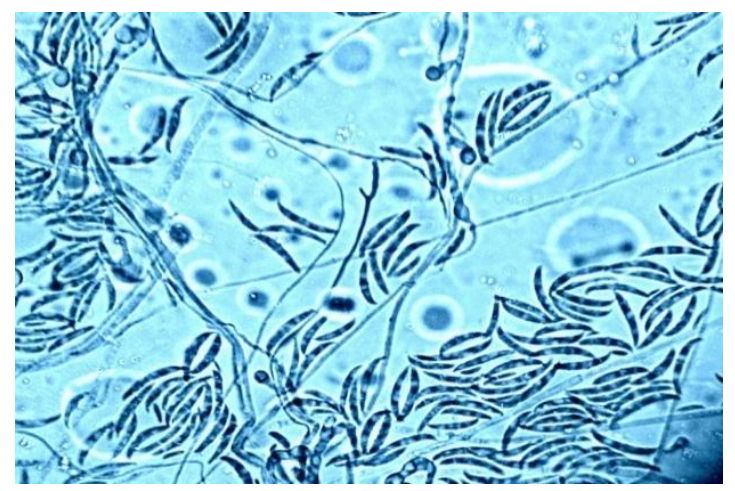

A. JFS $_{1}$

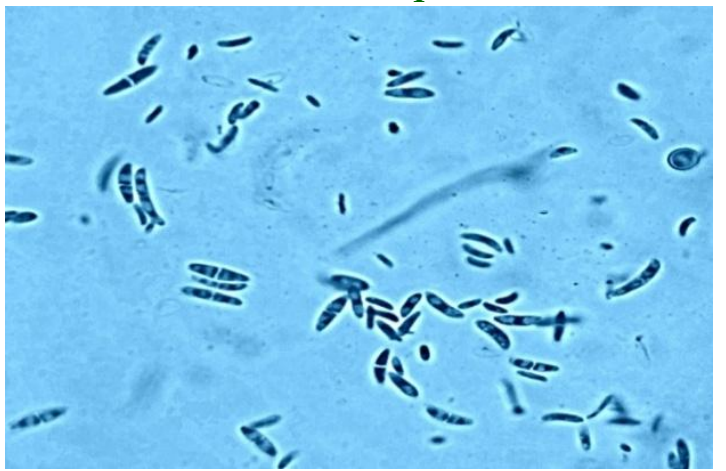

C. $\mathrm{NFS}_{3}$

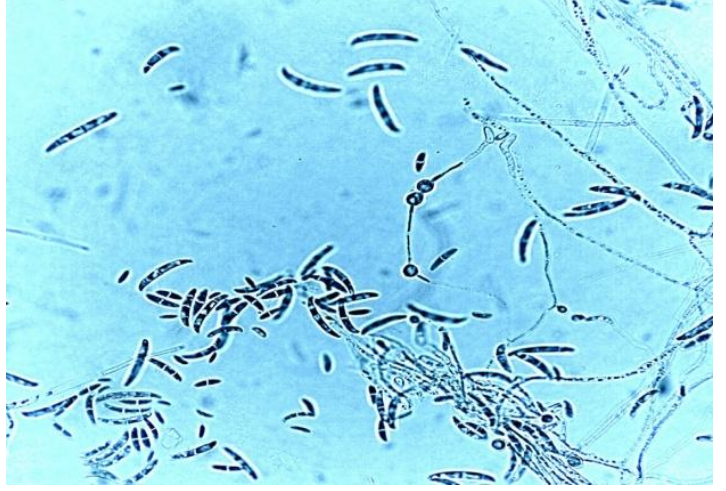

E. $\mathrm{NFS}_{5}$

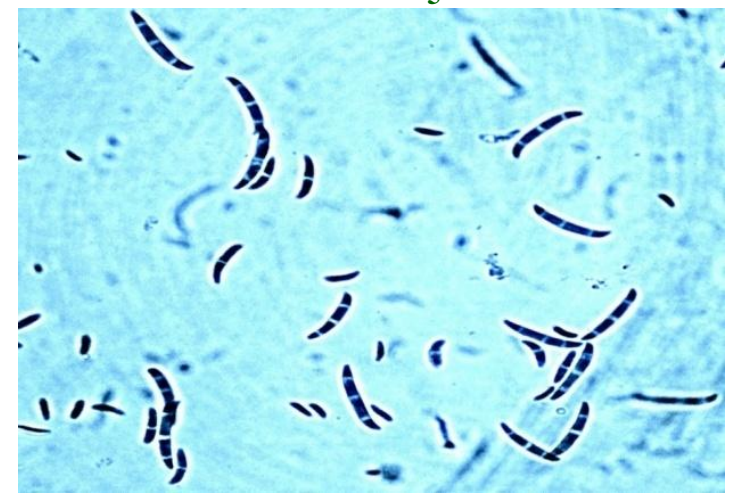

G. $\mathrm{BFS}_{7}$

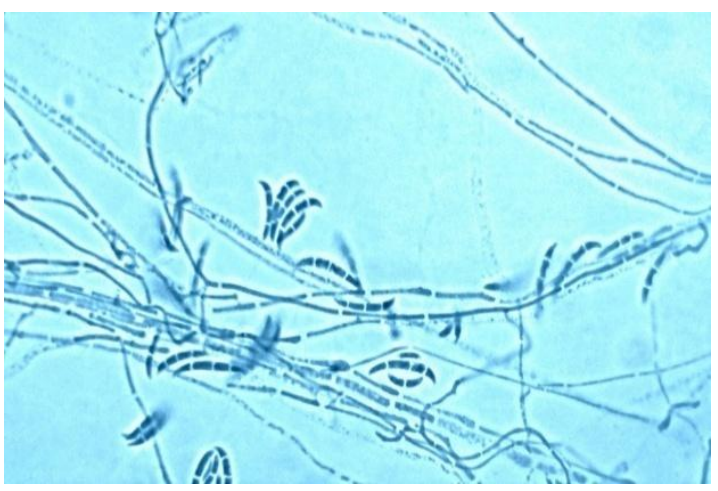

B. $\mathrm{JFS}_{2}$

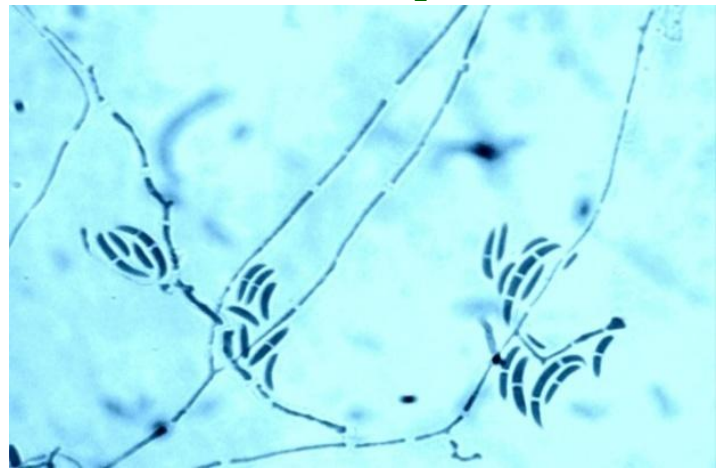

D. $\mathrm{NFS}_{4}$

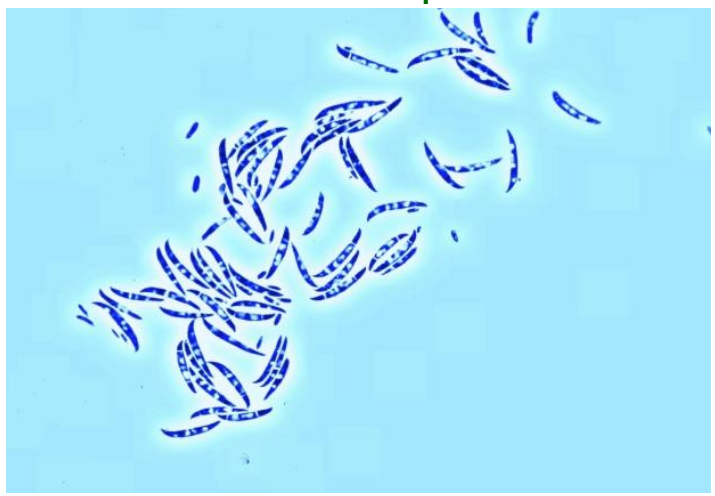

F. $\mathrm{BFS}_{6}$

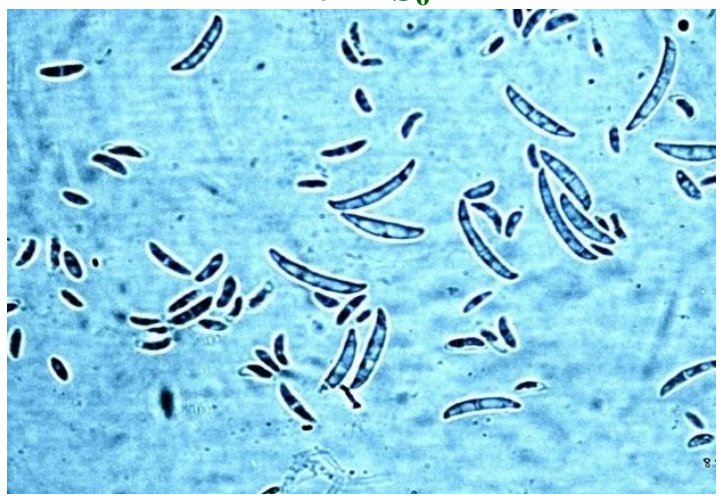

H. GFS $_{8}$

Plate.5 (A-H) Photomicrograph showing different isolates of macro-conidia of Fusarium solani $(40 \mathrm{X})$ 


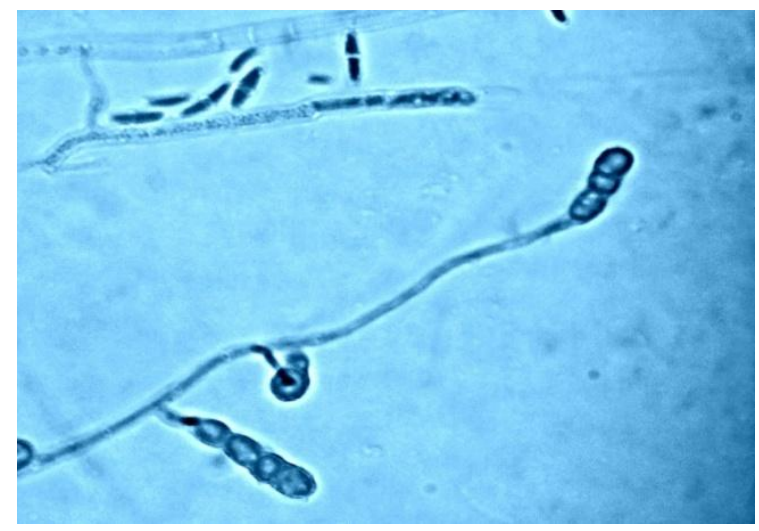

A. $\mathrm{JFS}_{1}$

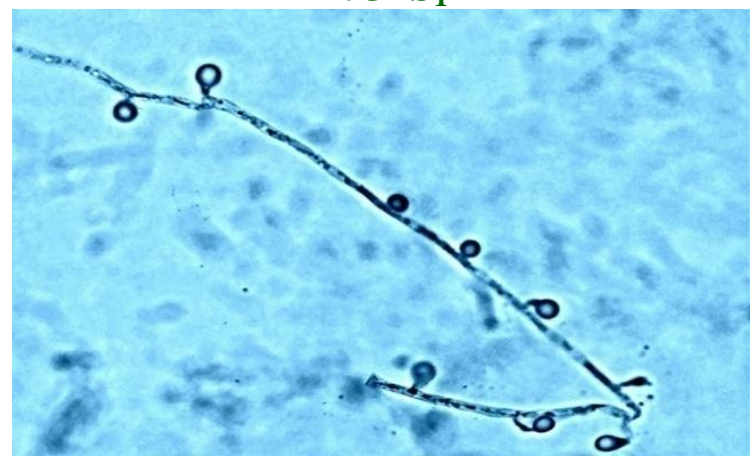

C. $\mathrm{NFS}_{3}$

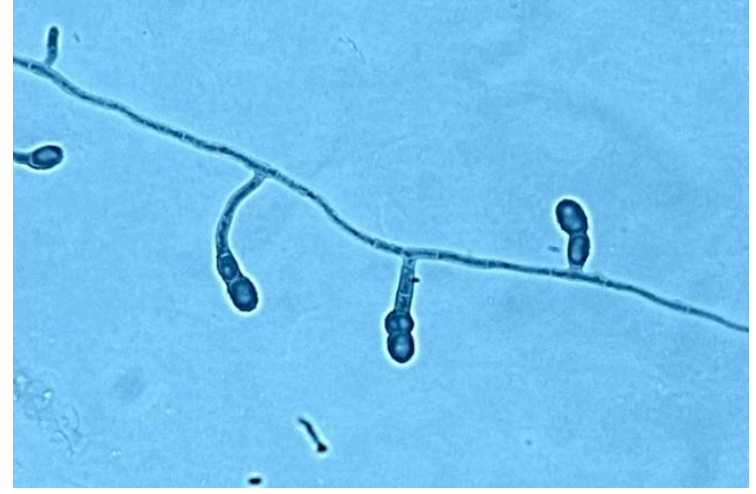

E. $\mathrm{NFS}_{5}$

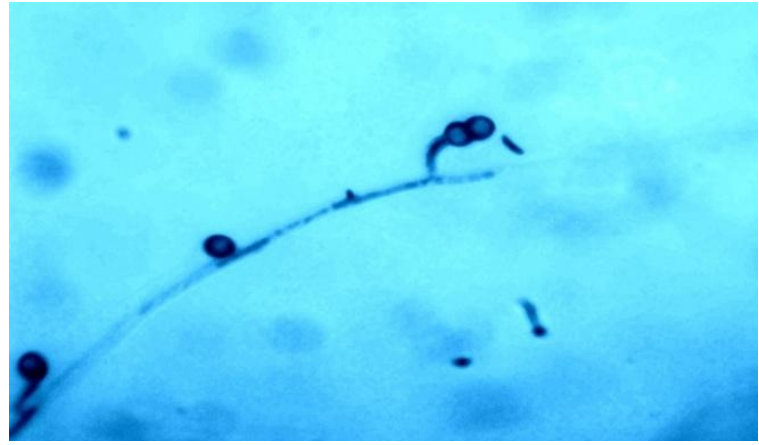

G. $\mathrm{BFS}_{7}$

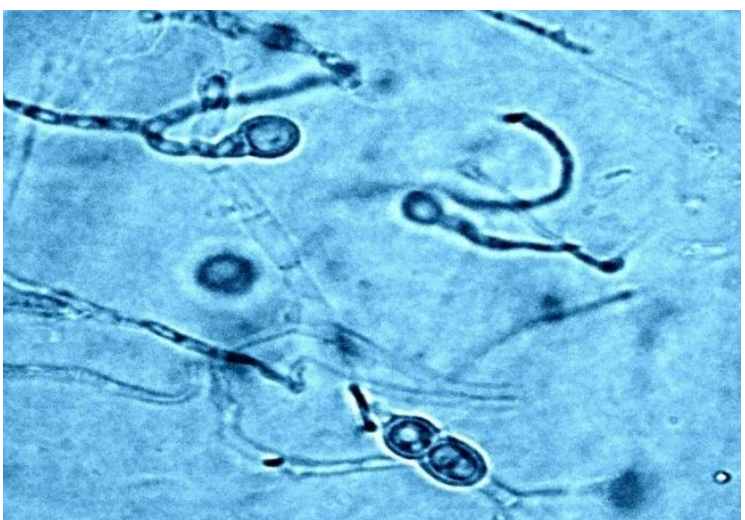

B. $\mathrm{JFS}_{2}$

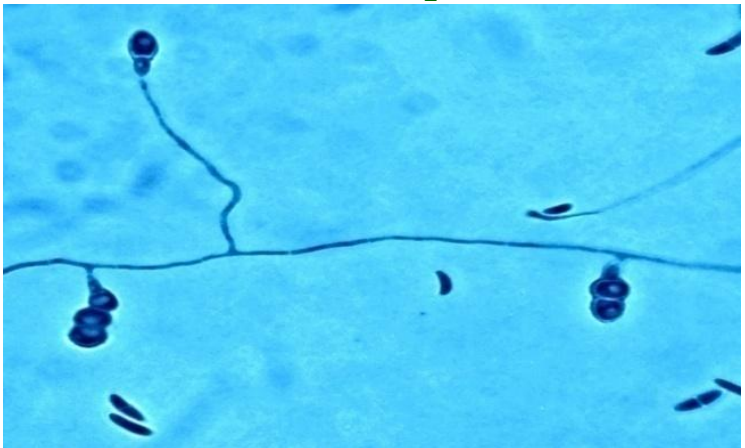

D. $\mathrm{NFS}_{4}$

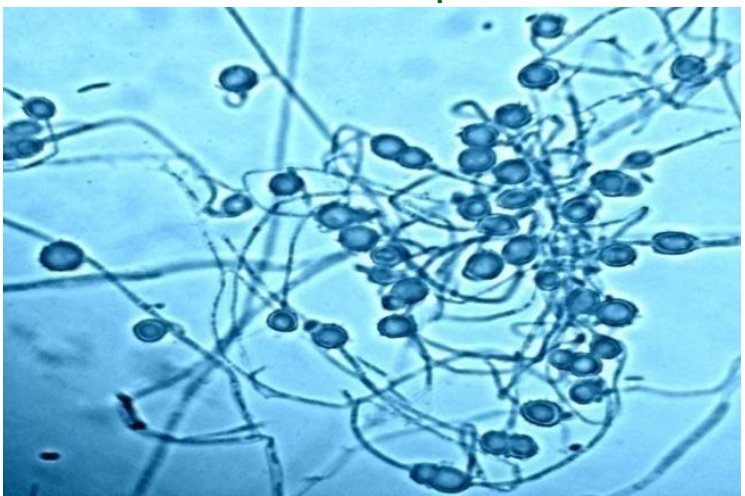

F. $\mathrm{BFS}_{6}$

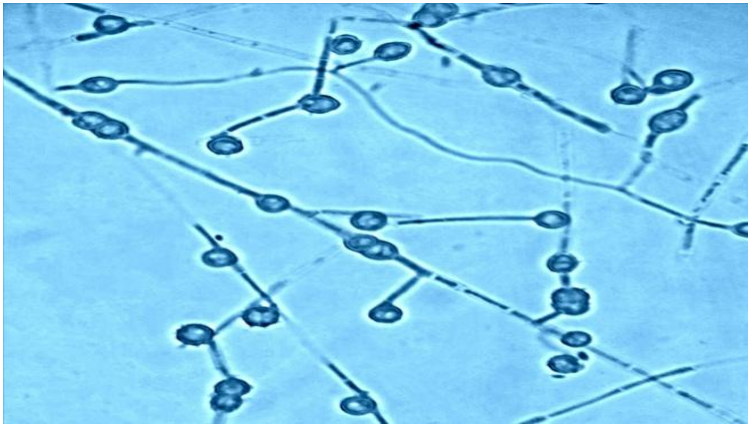

H. GFS 8

Plate.6 (A-H) Photomicrograph showing chlamydospores of different isolates of Fusarium solani (40X) 

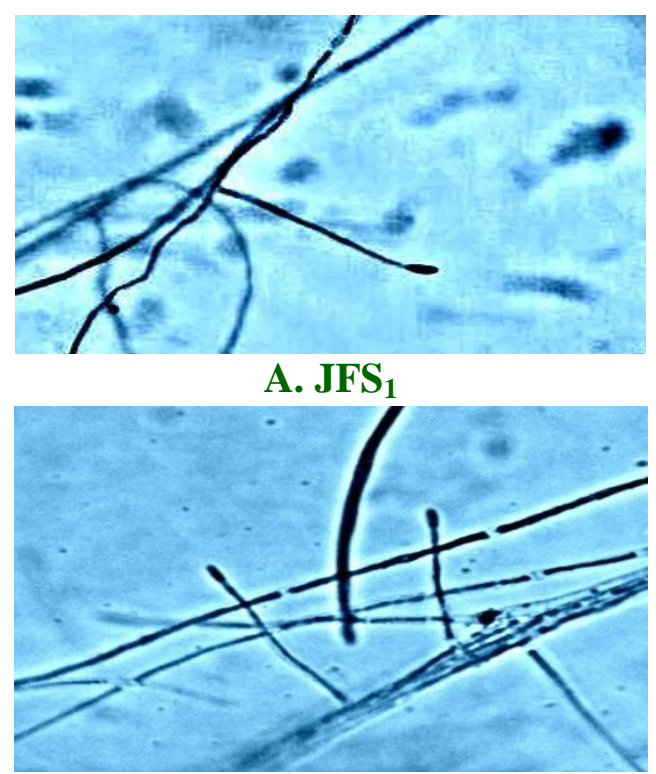

C. $\mathrm{NFS}_{3}$

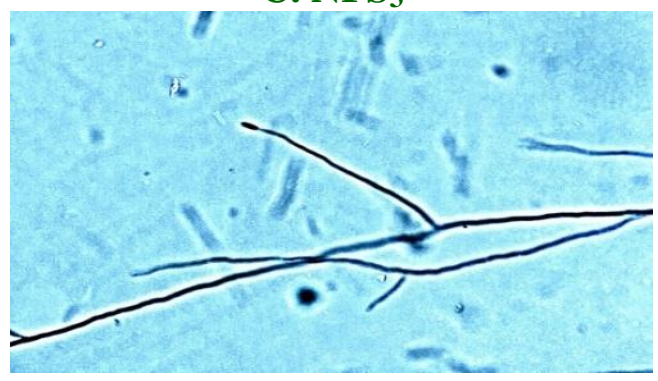

E. $\mathrm{NFS}_{5}$

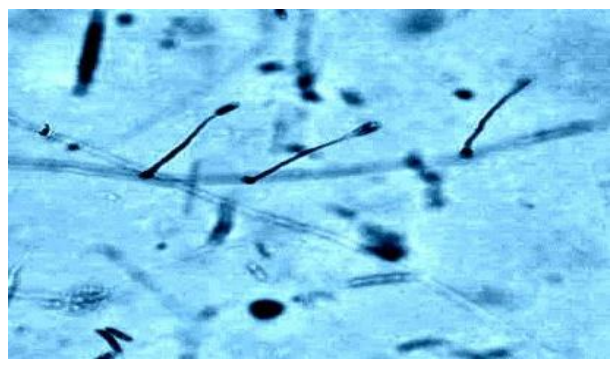

B. $\mathrm{JFS}_{2}$

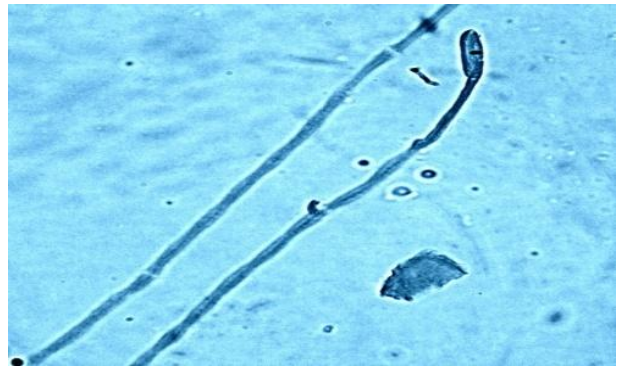

D. $\mathrm{NFS}_{4}$

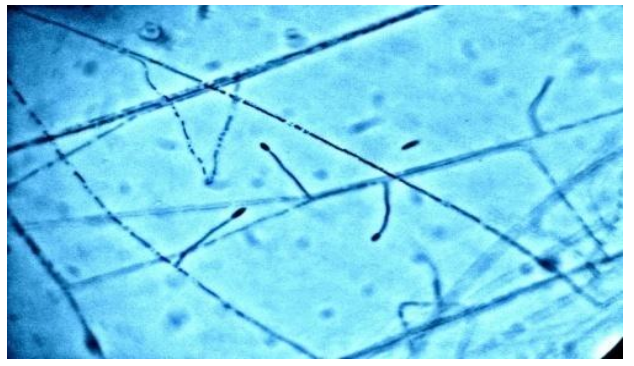

F. BFS $_{6}$

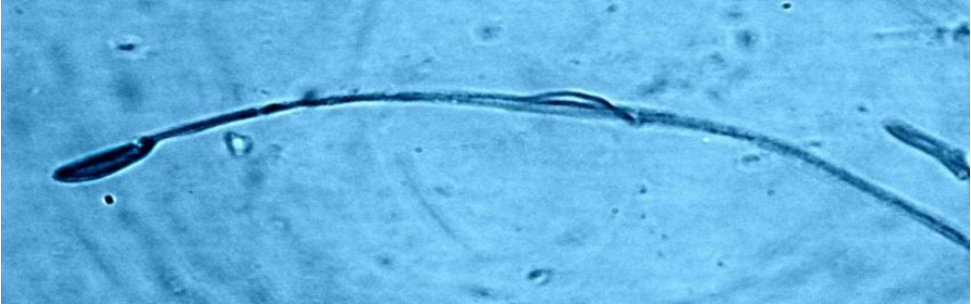

G. BFS $_{8}$

Plate.7 (A-G) Long monophialidic conidiogenous cells in different isolates of $F$. solani (40X)

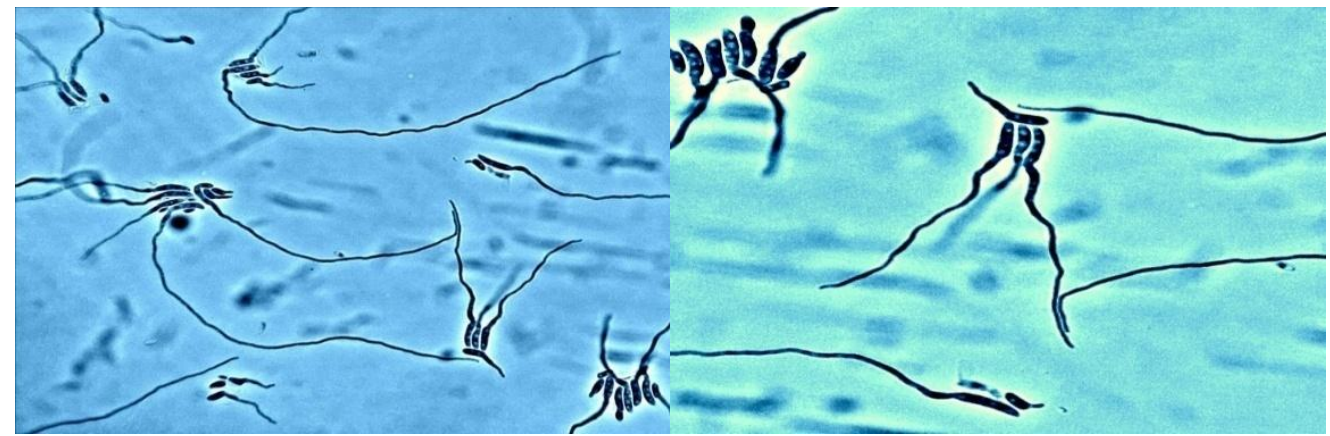

Plate.8 Germination of macro-conidia from single polar cell (40X) 
Table.1 Colony diameter (mm) of $F$. solani isolates up to 10 days after inoculation on PDA

\begin{tabular}{|c|c|c|c|c|c|c|c|c|}
\hline \multirow{3}{*}{$\begin{array}{c}\text { Isolates } \\
\text { No }\end{array}$} & \multirow{3}{*}{$\begin{array}{l}\text { Place of } \\
\text { isolation }\end{array}$} & \multicolumn{7}{|c|}{ *Colony diameter $(\mathrm{mm})$} \\
\hline & & 48 & 72 & 96 & 144 & 168 & 216 & 240 \\
\hline & & hrs & hrs & hrs & hrs & hrs & hrs & hrs \\
\hline $\mathrm{JFS}_{1}$ & Jorhat & 18.06 & 32.48 & 40.64 & 61.76 & 68.32 & 89.92 & 90.00 \\
\hline $\mathrm{JFS}_{2}$ & Jorhat & 16.38 & 28.10 & 35.60 & 52.69 & 62.28 & 84.86 & 90.00 \\
\hline $\mathrm{NFS}_{3}$ & Nagaon & 16.02 & 26.16 & 36.36 & 54.22 & 63.36 & 75.64 & 85.34 \\
\hline $\mathrm{NFS}_{4}$ & Nagaon & 17.84 & 27.84 & 36.62 & 59.54 & 67.40 & 85.46 & 90.00 \\
\hline $\mathrm{NFS}_{5}$ & Nagaon & 14.71 & 20.27 & 27.56 & 45.66 & 50.60 & 76.58 & 84.78 \\
\hline $\mathrm{BFS}_{6}$ & Biswanath & 14.56 & 19.37 & 24.46 & 52.30 & 60.30 & 84.88 & 87.46 \\
\hline $\mathrm{BFS}_{7}$ & Biswanath & 15.61 & 23.52 & 28.50 & 48.32 & 57.70 & 70.52 & 81.88 \\
\hline $\mathrm{GFS}_{8}$ & Golaghat & 16.60 & 27.54 & 33.50 & 56.46 & 64.70 & 76.76 & 87.56 \\
\hline \multicolumn{2}{|c|}{$\operatorname{SEm}( \pm)$} & 0.57 & 0.57 & 0.15 & 0.17 & 0.36 & 0.26 & 0.27 \\
\hline \multicolumn{2}{|c|}{$\mathrm{CD}(0.05)$} & 1.16 & 1.17 & 0.29 & 0.35 & 0.72 & 0.55 & 0.55 \\
\hline
\end{tabular}

Means within columns separated by Duncan's multiple range test $\mathrm{P}=0.05$

* Values are mean of five replications

Table.2 Colony characteristics of eight isolates of $F$. solani on PDA

\begin{tabular}{|l|l|l|l|}
\hline $\begin{array}{c}\text { Isolates } \\
\text { No }\end{array}$ & \multicolumn{1}{|c|}{ Colony characters } & \multicolumn{1}{|c|}{ *Pigmentation } & Colony margin \\
\hline $\mathrm{JFS}_{1}$ & $\begin{array}{l}\text { White colour cottony growth } \\
\text { and raised mycelium }\end{array}$ & Purple group 75 (B) & Smooth margin \\
\hline $\mathrm{JFS}_{2}$ & $\begin{array}{l}\text { White cottony with fluffy } \\
\text { growth mycelium }\end{array}$ & Purple group 75 (A) & Smooth margin \\
\hline $\mathrm{NFS}_{3}$ & White dense growth & Yellow group 12 (D) & Smooth margin \\
\hline $\mathrm{NFS}_{4}$ & White sparse growth & Yellow orange 14 group (B) & Smooth margin \\
\hline $\mathrm{NFS}_{5}$ & White colour fluffy growth & Yellow group 12 (C) & Irregular margin \\
\hline $\mathrm{BFS}_{6}$ & White fluffy mycelium & Yellow group 12 (C) & Irregular margin \\
\hline $\mathrm{BFS}_{7}$ & $\begin{array}{l}\text { White fluffy mycelium with } \\
\text { concentric ring }\end{array}$ & Yellow orange 14 group (A) & Irregular margin \\
\hline $\mathrm{GFS}_{8}$ & $\begin{array}{l}\text { White raised cottony } \\
\text { mycelium }\end{array}$ & Orange group 28 (C) & Irregular margin \\
\hline
\end{tabular}

* Royal Horticultural Society Colour Chart 
Table.3 Morphological characteristics of different isolates of $F$. solani on PDA

\begin{tabular}{|c|c|c|c|c|c|c|c|}
\hline \multirow[b]{2}{*}{$\begin{array}{c}\text { Isolates } \\
\text { No }\end{array}$} & \multicolumn{2}{|c|}{ Spore size $(\mu \mathrm{m})$} & \multicolumn{2}{|c|}{ Septation } & \multicolumn{2}{|c|}{ Shape } & \multirow[b]{2}{*}{ Colour } \\
\hline & $\begin{array}{c}\text { Micro } \\
\text { conidia } \\
(\mathrm{L} \times \mathrm{B}) \\
\end{array}$ & $\begin{array}{l}\text { Macro } \\
\text { conidia } \\
(\mathbf{L} \times \text { B }) \\
\end{array}$ & $\begin{array}{c}\text { Micro } \\
\text { conidia }\end{array}$ & $\begin{array}{l}\text { Macro } \\
\text { conidia }\end{array}$ & $\begin{array}{l}\text { Macro } \\
\text { conidia }\end{array}$ & $\begin{array}{c}\text { Micro } \\
\text { conidia }\end{array}$ & \\
\hline $\mathrm{JFS}_{1}$ & $\begin{array}{c}(5.53-8.59) \\
X \\
(2.33-2.63) \\
\end{array}$ & $\begin{array}{c}(22.36-28.92) \\
X \\
(3.78-4.32) \\
\end{array}$ & $0-1$ & $3-4$ & $\begin{array}{l}\text { Elongated with } \\
\text { blunt ends }\end{array}$ & $\begin{array}{l}\text { Round } \\
\text { to oval }\end{array}$ & Hyaline \\
\hline $\mathrm{JFS}_{2}$ & $\begin{array}{c}(3.94-7.04) \\
X \\
(1.98-2.40)\end{array}$ & $\begin{array}{c}(21.16-25.44) \\
X \\
(2.65-3.87) \\
\end{array}$ & $0-1$ & $3-4$ & $\begin{array}{c}\text { Sickle shaped } \\
\text { with blunt ends }\end{array}$ & $\begin{array}{l}\text { Round } \\
\text { to oval }\end{array}$ & Hyaline \\
\hline $\mathrm{NFS}_{3}$ & $\begin{array}{c}(5.3-8.52) \\
X \\
(2.27-2.59) \\
\end{array}$ & $\begin{array}{c}(17.39-23.17) \\
X \\
(2.91-4.51) \\
\end{array}$ & $0-1$ & $2-3$ & Sickle shaped & $\begin{array}{l}\text { Round } \\
\text { to oval }\end{array}$ & Hyaline \\
\hline $\mathrm{NFS}_{4}$ & $\begin{array}{c}(9.85-12.69) \\
X \\
(2.60-4.14)\end{array}$ & $\begin{array}{c}(23.88-29.24) \\
X \\
(3.21-4.97)\end{array}$ & $0-1$ & $3-4$ & $\begin{array}{l}\text { Elongated with } \\
\text { blunt ends }\end{array}$ & $\begin{array}{l}\text { Round } \\
\text { to oval }\end{array}$ & Hyaline \\
\hline $\mathrm{NFS}_{5}$ & $\begin{array}{c}(9.54-11.56) \\
X \\
(2.74-4.04) \\
\end{array}$ & $\begin{array}{c}(26.42-32.46) \\
X \\
(3.24-4.74) \\
\end{array}$ & $0-1$ & $3-4$ & $\begin{array}{l}\text { Elongated with } \\
\text { blunt ends }\end{array}$ & $\begin{array}{l}\text { Round } \\
\text { to oval }\end{array}$ & Hyaline \\
\hline $\mathrm{BFS}_{6}$ & $\begin{array}{c}(7.58-11.47) \\
X \\
(2.68-3.56) \\
\end{array}$ & $\begin{array}{c}(23.99-32.63) \\
X \\
(5.10-6.26) \\
\end{array}$ & $0-1$ & $3-4$ & Sickle shaped & $\begin{array}{l}\text { Round } \\
\text { to oval }\end{array}$ & Hyaline \\
\hline $\mathrm{BFS}_{7}$ & $\begin{array}{c}(9.72-13.04) \\
X \\
(1.40-2.68) \\
\end{array}$ & $\begin{array}{c}(25.32-29.78) \\
X \\
(4.35-5.81) \\
\end{array}$ & $0-1$ & $2-3$ & Sickle shaped & $\begin{array}{l}\text { Round } \\
\text { to oval }\end{array}$ & Hyaline \\
\hline $\mathrm{GFS}_{8}$ & $\begin{array}{c}(7.82-9.60) \\
X \\
(2.26-3.14) \\
\end{array}$ & $\begin{array}{c}(22.55-26.11) \\
X \\
(3.63-4.95) \\
\end{array}$ & $0-1$ & $2-3$ & $\begin{array}{c}\text { Sickle shaped } \\
\text { with blunt ends }\end{array}$ & $\begin{array}{l}\text { Round } \\
\text { to oval }\end{array}$ & Hyaline \\
\hline
\end{tabular}

\section{Morphological characteristics on PDA}

The fungus $F$. solani produced two types of asexual spores viz., micro and macro conidia. The resting spores namely chlamydospores also were observed in 10-15 days age old cultures. The size of micro and macro conidia was ranged from (3-4 x 1-2) to $(9-10 \times 1-3) \mu \mathrm{m}$ and (26.42-32.46) X (3.24-4.74) $\mu \mathrm{m}$ to (17.3923.17) $X$ (2.91-4.51) $\mu \mathrm{m}$ respectively, the number of septa in micro and macro conidia are $0-1$ and 2-4 respectively and the colour is hyaline. The shape of macroconidia is sickle shaped and elongated with blunt ends and microconidia is round to oval shaped. The chlamydospores were oval, intercalary and terminal among the isolates (Table 3). The most distinguished characters of long monophialidic conidiogenous cells were observed in all the isolates. Conidiophores were elongated and sparsely branched, each branch usually terminated with a spore bearing phialid. The maximum size of macroconidia was observed in isolates $\mathrm{NFS}_{5}(26.42-32.46) \mathrm{X}(3.24-4.74) \mu \mathrm{m}$ and $\mathrm{BFS}_{6}$ (23.99-32.63) $\mathrm{X}(5.10-6.26) \mu \mathrm{m}$ followed by isolates $\mathrm{BFS}_{7}(25.32$-29.78) $\mathrm{X}$ (4.35-5.81) $\mu \mathrm{m}, \mathrm{NFS}_{4}(23.88-29.24) \mathrm{X}(3.21-$ 4.97) $\mu \mathrm{m}, \mathrm{JFS}_{1}(22.36$ - 28.92) X (3.78-4.32) $\mu \mathrm{m}, \mathrm{GFS}_{8}(22.55-26.11) X(3.63-4.95) \mu \mathrm{m}$ and $\mathrm{JFS}_{2}(21.16-25.44) \mathrm{X}(2.65-3.87) \mu \mathrm{m}$ whereas minimum macro conidia was observed in isolate $\mathrm{NFS}_{3}$ (17.39-23.17) X (2.91-4.51) $\mu \mathrm{m}$. The maximum size of micro conidia was observed in isolates $\mathrm{NFS}_{4}(9.85-12.69) \mathrm{X}(2.60-4.14) \mu \mathrm{m}$ 
and $\quad \mathrm{BFS}_{7} \quad(9.72-13.04) \quad \mathrm{X} \quad(1.40-2.68) \quad \mu \mathrm{m}$ followed by isolates $\mathrm{NFS}_{5}(9.54-11.56) \mathrm{X}$ (2.744.04) $\mu \mathrm{m}, \mathrm{GFS}_{8}(7.82-9.60) \mathrm{X}(2.26-3.14) \mu \mathrm{m}$, $\mathrm{BFS}_{6}(7.58-11.47) X(2.68-3.56) \mu \mathrm{m}, \mathrm{JFS}_{1}(5.53-$ 8.59) $X(2.33-2.63) \mu \mathrm{m}$, and $\mathrm{NFS}_{3}(5.3-8.52) X$ (2.27-2.59) $\mu \mathrm{m}$ whereas minimum microconidia was observed in isolate $\mathrm{JFS}_{2}$ (3.94-7.04) X (1.98-2.40) $\mu \mathrm{m}$. Sreedevi et al., (2009) observed that the size of micro and macro conidia of $F$. solani causing root rot of patchouli ranged from (6.60-19.80 x 3.30-6.60) $\mu \mathrm{m}$ and (29.70-47.85 x 4.95-6.60) $\mu \mathrm{m}$, respectively. The description of the pathogen is in agreement with that of $F$. solani (Mart.) Sacc. Booth (1971) as observed by Chandran et al., (2012).

\section{Acknowledgement}

The authors thank Department of Plant Pathology and Directorate of Post-Graduate studies, Assam Agricultural University (AAU), Jorhat, Assam, India for providing all possible facilities for present study.

\section{References}

Booth C., 1971. The genus Fusarium. Commonwealth Mycological Institute, Kew Surrey, England, pp.132.

Champawat, R.S. and Pathak, V.N. 1989. Cultural, morphological and pathogenic variations in Fusarium oxysporum f.sp. cumini. Indian J. Mycol. Pl. Pathol. 19(2): 178-183.

Chandran, M.R. and Kumar, M.R. 2012. Studies on cultural, morphological variability in isolates of Fusarium solani (Mart.) Sacc, incitant of dry root-rot of Citrus. Curr. Biotica. 6(2): 152-162.

Chavan, S.C.; Hegde, Y.R. and Prashanthi, S.K. 2009. Management of wilt of patchouli caused by Fusarium solani. J. Mycol. Pl.
Pathol. 39(1): 32-34.

Das, K. (2001). Patchouli: The wonder plant, north-east. Sun, pp. 32.

Jadhav, S.G., Jadhav, B.B. and Apte, U.B., 2003, Influence of growth regulators on growth and oil content of Patchouli. Indian Perf., 46: 287-289.

Kore, S.S. and Mashalkar, S.I. 1987. Dry rot diseases of sapota caused by Fusarium solani (Mart.) Sacc. J. Maharashtra Agril. Univ. 12: 279-282.

Kore, S.S. and Patil, D.S. 1985. Dry rot disease of mango seedling caused by Fusarium solani. J. Mycol. Pl. Pathol. 15: 287-288.

Kumar A, Gauniyal AK, Virmani O.P. 1986. Cultivation of Pogostemon cablin for its oil. Curr. Res. Med. Aromatic Plants 8(2): 79-86.

Madhukeshwara, S.S. 2000. Studies on variation and management of Fusarium wilt of pigeonpea (Cajanus cajan). M.Sc. (Agri.) Thesis, UAS, GKVK, Bangalore, pp. 85-94.

Puttanna, K., Prakasa Rao, E V S., Ganesha Rao, R.S., Gopinath, C.T. and Ramesh, S. 2005. Effect of shade and nitrogen on herb yield and longevity of Patchouli (Pogostemon cablin). J. Med. Arom. Pl. Sci, 25: 297-300.

Satyaprasad, K. and Rama, R.P. 1981. Root rot of guar caused by Fusarium solani. Indian Phytopath. 34: 523-524.

Singh, M. and Rao, G.R.S. 2009. Influence of sources and doses of $\mathrm{N}$ and $\mathrm{K}$ on herbage, oil yield and nutrient uptake of patchouli Pogostemon cablin (Blanco) Benth. Ind. Crops Prod. 29: 229-234.

Vettraino, A.M.; Shresha, G.P. and Vannini, A 2009. First report of Fusarium solani wilt of Olea europaea in Nepal. Plant Dis. 93: 200.

\section{How to cite this article:}

Monuj Gogoi, D.K. Sarmah and Ali, S. 2017. Cultural and Morphological Variations of Fusarium solani (Mart.) Sacc. Causing Root Rot of Patchouli in Assam. Int.J.Curr.Microbiol.App.Sci. 6(11): 1889-1901. doi: https://doi.org/10.20546/ijcmas.2017.611.225 